\author{
Military Technical College \\ Kobry Elkobbah, \\ Cairo, Egypt
}

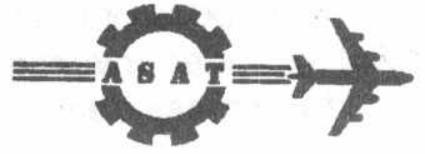

$8^{\text {th }}$ International Conference on Aerospace Sciences \& Aviation Technology

\title{
SOLUTION OF DYNAMIC FLUID-STRUCTURE INTERACTION USING STANDARD FINITE ELEMENT PACKAGE
}

\begin{abstract}
The modal properties of fluid-structure system were investigated. A standard finite element software (COSMOS) was adapted to detect the modal properties of a tank partially filled with liquid. A concentrated mass element was added to the nodes of the wet part of the tank to resemble the fluid influence. Experimental work was conducted to help devise an empirical relation for the added mass relative to that of the fluid. The validity of the method was confirmed through laboratory measurements and comparison of results with the published work, which demonstrated good
agreement.
\end{abstract}

Ibrahim H.K.", El-Maddah M.M.", El-Senbawi M.A."

\section{KEY WORDS}

Fluid-Structure Interaction, Finite Elements, Cylindrical Tank, Mode Shapes, modal patterns, modal characteristics, Added mass, Dynamics.

\section{INTRODUCTION}

Fluid-structure interaction phenomenon is one of the well-known kinds of coupled problems. In coupled problems, neither the fluid nor the structural system can be solved independently of the other due to the unknown interface forces. In a very considerable range of problems, the fluid displacement remains small while interaction is substantial. In this category the structural motions influence and react with the generation of pressures in a reservoir or container [1]. Solution of the problem of fluid-structure interaction is linked with the progress in finite element method (FEM) [2-6], boundary element method (BEM) [7-9], and analytical methods. Such techniques, also, may be mixed together to assess the solution. Yet, semianalytical solutions and mixed FEM-BEM are developed too [10-12].

The objective of the present work is to examine the influence of the fluid-structure interaction on the modal properties of the tank structure. To accomplish this objective, the standard finite element software COSMOSIM was used to discretize the tank structure using shell elements (SHELL2D) and the modal properties of empty structure were deduced. For partially filled tank, the concentrated mass

* Assistant, Military Technical College.

*. Prof., Military Technical College.

** Ph.D., Military Technical College. 
element (MASS) was added to the wet nodes of the structure. The concept of added mass was adopted for the problem under investigation through constructing an empirical equation to estimate the added mass defined as:

$$
\xi=\frac{\mathrm{m}_{\text {add }}}{\mathrm{m}_{\mathrm{f}}}
$$

where $m_{a d d}$ is a structural mass which should be added to the empty tank structure, and $m_{f}$ is the fluid mass. In this way a proper value of mass is added at the nodes of the wet surface of the structure such that an effect equivalent to the presence of the fluid is produced. To conclude this equation it was necessary to make use of some measured values. The results were confirmed throughout comparison with available data.

\section{RESULTS OF EMPTY TANK}

Hammer test technique is used to plot the mobility curves of the empty tank and partially filled one. It is found that optimum tank dimensions, to yield more than 5 modes of vibration below $500 \mathrm{~Hz}$, are: length $90 \mathrm{~cm}$, diameter $30 \mathrm{~cm}$ and thickness $1 \mathrm{~mm}$. This choice discards the disadvantaged of hammer testing and renders more obvious the influence of filing level on modal properties. To achieve the free boundary conditions of the lest, the tank is hanged using rubber ropes having very small stiffness relative to that of the tank.

Table(1) introduces the results of the natural frequencies of the empty tank. Figure (1) shows the descretization of the tank structure to finite elements. Figure (2) shows the first five mode shapes of the cylindrical part of the empty tank. The obtained mode shapes of empty tank agree with those obtained by Lee["13]. which are illustrated in Fig.(3).

Table 1 Natural frequencies of the empty tank

\begin{tabular}{|c|c|c|}
\hline Frequency Number & Frequency $(\mathrm{Hz})$ & Notes \\
\hline 1 & 102.372 & bottom \\
\hline 2 & 106.500 & bottom \\
\hline 3 & 167.694 & \\
\hline 4 & 167.694 & \\
\hline 5 & 178.432 & \\
\hline 6 & 178.447 & \\
\hline 7 & 212.475 & bottom \\
\hline 8 & 212.475 & bottom \\
\hline 9 & 212.664 & bottom \\
\hline 10 & 212.664 & bottom \\
\hline 11 & 257.002 & \\
\hline 12 & 257.002 & \\
\hline 13 & 291.513 & \\
\hline 14 & 292.153 & \\
\hline 15 & 331.986 & \\
\hline 16 & 332.058 & \\
\hline
\end{tabular}




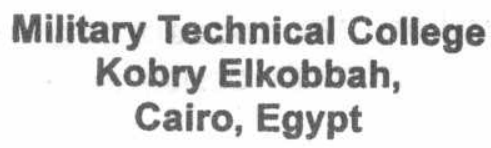

$8^{\text {th }}$ International Conference on Aerospace Sciences \& Aviation Technology

\title{
SOLUTION OF DYNAMIC FLUID-STRUCTURE INTERACTION USING STANDARD FINITE ELEMENT PACKAGE
}

\begin{abstract}
The modal properties of fluid-structure system were investigated. A standard finite element software (COSMOS) was adapted to detect the modal properties of a tank partially filled with liquid. A concentrated mass element was added to the nodes of the wet part of the tank to resemble the fluid influence. Experimental work was conducted to heip devise an empirical relation for the added mass relative to that of the fluid. The validity of the method was confirmed through laboratory measurements and comparison of results with the published work, which demonstrated good agreement.
\end{abstract}

Ibrahim H.K. , El-Maddah M.M."

\section{KEY WORDS}

Fluid-Structure Interaction, Finite Elements, Cylindrical Tank, Mode Shapes, modal patterns, modal characteristics, Added mass, Dynamics.

\section{INTRODUCTION}

Fluid-structure interaction phenomenon is one of the well-known kinds of coupled problems. In coupled problems, neither the fluid nor the structural system can be solved independently of the other due to the unknown interface forces. In a very considerable range of problems, the fluid displacement remains small while interaction is substantial. In this category the structural motions influence and react with the generation of pressures in a reservoir or container [1]. Solution of the problem of fluid-structure interaction is linked with the progress in finite element method (FEM) [2-6], boundary element method (BEM) [7-9], and analytical methods. Such techniques, also, may be mixed together to assess the solution. Yet, semianalytical solutions and mixed FEM-BEM are developed too [10-12].

The objective of the present work is to examine the influence of the fluid-structure interaction on the modal properties of the tank structure. To accomplish this objective, the standard finite element software COSMOSIM was used to discretize the tank structure using shell elements (SHELL2D) and the modal properties of empty structure were deduced. For partially filled tank, the concentrated mass

\footnotetext{
* Assistant, Military Technical College.

*. Prof., Military Technical College.

*** Ph.D., Military Technical College.
} 
element (MASS) was added to the wet nodes of the structure. The concept of adided mass was adopted for the problem under investigation through constructing an empirical equation to estimate the added mass defined as:

$$
\xi=\frac{m_{\text {sdd }}}{m_{f}}
$$

where $m_{\text {add }}$ is a structural mass which should be added to the empty tank structure, and $m_{f}$ is the fluid mass. In this way a proper value of mass is added at the nodes of the wet surface of the structure such that an effect equivalent to the presence of the fluid is produced. To conclude this equation it was necessary to make use of some measured values. The results were confirmed throughout comparison with available data.

\section{RESULTS OF EMPTY TANK}

Hammer test technique is used to plot the mobility curves of the empty tank and partially filled one. It is found that optimum tank dimensions, to yield more than 5 modes of vibration below $500 \mathrm{~Hz}$, are: length $90 \mathrm{~cm}$, diameter $30 \mathrm{~cm}$ and thickness $1 \mathrm{~mm}$. This choice discards the disadvantaged of hammer testing and renders more obvious the influence of filing level on modal properties. To achieve the free boundary conditions of the lest, the tank is hanged using rubber ropes having very small stiffness relative to that of the tank.

Table(1) introduces the results of the natural frequencies of the empty tank. Figure (1) shows the descretization of the tank structure to finite elements. Figure (2) shows the first five mode shapes of the cylindrical part of the empty tank. The obtained mode shapes of empty tank agree with those obtained by Lee['13]. which are illustrated in Fig.(3).

Table 1 Natural frequencies of the empty tank

\begin{tabular}{|c|c|c|}
\hline Frequency Number & Frequency $(\mathrm{Hz})$ & Notes \\
\hline 1 & 102.372 & bottom \\
\hline 2 & 106.500 & bottom \\
\hline 3 & 167.694 & \\
\hline 4 & 167.694 & \\
\hline 5 & 178.432 & \\
\hline 6 & 178.447 & \\
\hline 7 & 212.475 & bottom \\
\hline 8 & 212.475 & bottom \\
\hline 9 & 212.664 & bottom \\
\hline 10 & 212.664 & bottom \\
\hline 11 & 257.002 & \\
\hline 12 & 257.002 & \\
\hline 13 & 291.513 & \\
\hline 14 & 292.153 & \\
\hline 15 & 331.986 & \\
\hline 16 & 332.058 & \\
\hline
\end{tabular}




\section{CONSTRUCTION OF THE EMPIRECAL EQUATION}

Usually, the complete model of the fluid and tank structure is too complicated to construct and too tedious to solve. The packages with such capabilities are expensive and may be not available. Here, it is intended to use a simplified method to determine the added mass which can be allocated to finite element model of the empty tank to resemble the effect of fluid-structure interaction.

One of the simplest methods to tackle such a problem is to construct an empirical equation for the needed quantities. Construction of this type of equations needs experience to choose the proper parameters that will greatly affect the phenomenon. In the studied case, many parameters may affect the fluid-structure interaction. The physical properties of the structure are affecting the modal properties of the structure itself whatever it is empty, partially-filled, or completely filled with fluid. While for fluid, the main physical property that has an influence on the interaction is the density of the fluid and this quantity is implicitly included in the added mass method. On the other hand, the geometric parameters are greatly affecting the interaction. Many geometric parameters may appear to be the key-parameter in these phenomena; such as dimensions of the tank and height of fluid filling. It is suitable to use a nondimensional quantity in the empirical equation to give it the generality for different dimensions. Housner [14], El-Sherief [15], Lee [13] and others use the nondimensional fluid height as the key-parameter in the evaluation of the fluid-structure interaction problems. The non-dimensional fluid height is defined as

$$
\bar{H}=\frac{H}{D}
$$

where $\mathrm{H}$ is the fluid depth in the horizontal tank and $\mathrm{D}$ is the tank diameter.

This reflects the importance of this value because it indicates directly the quantity of contained fluid. The non-dimensional height increases linearly with the increase of filling level, which facilitates the construction of the empirical relation.

The experimental results are used to quantify the percentage of the fluid mass to be added to the wetted part. As a first step, the results of the experimental work, listed in Table (2), are averaged for each filling level as indicated in Table (3). Then, the standard software COSMOSIM is used to get the natural frequencies of the tank model with added mass elements on the wetted nodes. Different percentages of the original fluid mass are tried to get the closest results to the experimental values. After that, the results are plotted. The best fitting curve is found. The percentage of the added mass $\zeta$ is found to change as follows:

$$
\zeta=0.385 \bar{H}^{-0.4}
$$
Figure (4) illustrates the non-dimensional height and the percentage function as
related to the filling level. 


\section{VERIFICATION}

After adaptation of the added mass method for solving the fluid-structure interaction problem, the proposed empirical equation for the percentage of the fluid mass added to the wetted surface has to be verified. The equation is applied to the original model and error courses are plotted. Figures (5) through (9) show the difference between the theoretical and the experimental determination of natural frequencies. It is observed that almost in all cases the error does not exceed $9 \%$ while in odd cases is less than $13 \%$. Reasonably, this falls within the limits of acceptable error ranges obtained by Qinque [16].

Another verification is done using the work of Ohayon [17]. It is the only available work that treats the fluid-structure interaction for contained fluid in horizontal free-free cylindrical tank with flat bottoms. They established symmetric variational formulation for the problem of transient and modal analysis of bounded coupled fluicl-structure linear systems, taking into account gravity and compressibility effects. The proposed method is applied to a cylindrical tank of length $1.73 \mathrm{~m}$ and diameter $0.173 \mathrm{~m}$. The results are compared to the experimental work of Dupriez [18]. The proposed tank is modeled using the present method and results are compared with those obey Ohayon method and the experimental results of Dupriez. Tables (3) and (4) summarize the results for half-filled and three-quarter-filled tanks, resspectively. Tables show good agreement of results with previous works.

Table 2 Averaged natural frequencies for different filling levels

\begin{tabular}{|c|c|c|c|c|c|c|c|c|}
\hline \multirow{2}{*}{$\begin{array}{c}\text { Filling } \\
\text { Level }\end{array}$} & 1 & 2 & 3 & 4 & 5 & 6 & 7 & 8 \\
\hline 0 & 161.25 & 168.95 & 177.24 & 247.49 & 251.66 & 294.58 & 302.50 & 341.24 \\
\hline $10 \%$ & 99.79 & 106.66 & 162.08 & 167.18 & 212.91 & 251.25 & 272.08 & 303.54 \\
\hline $25 \%$ & 83.12 & 85.83 & 135.00 & 151.04 & 189.58 & 218.54 & 242.08 & 251.25 \\
\hline $50 \%$ & 74.25 & 76.37 & 109.37 & 118.95 & 158.43 & 167.50 & 172.50 & 178.74 \\
\hline $75 \%$ & 71.45 & 73.12 & 90.62 & 96.25 & 126.25 & 135.00 & 154.58 & 183.95 \\
\hline $90 \%$ & 70.20 & 71.25 & 81.24 & 95.41 & 107.29 & 119.37 & 127.91 & 156.66 \\
\hline
\end{tabular}

Table 3 Comparison between present-work results and previous-work results for half-filled tank

\begin{tabular}{|c|c|c|c|c|c|}
\hline $\begin{array}{c}\text { Present } \\
\text { method } \\
{[\mathrm{Hz}]}\end{array}$ & $\begin{array}{c}\text { Dupriez } \\
\text { (experimental) } \\
{[\mathrm{Hz}]}\end{array}$ & $\begin{array}{c}\text { Relative } \\
\text { error }[\%] \\
\frac{f_{p}-f_{0}}{f_{p}} \times 100\end{array}$ & $\begin{array}{c}\text { Present } \\
\text { method } \\
{[\mathrm{Hz}]}\end{array}$ & $\begin{array}{c}\text { Ohayon } \\
\text { (numerical) } \\
{[\mathrm{Hz}]}\end{array}$ & $\begin{array}{c}\text { Relative } \\
\text { error }[\%] \\
\frac{f_{p}-f_{0}}{f_{p}} \times 100\end{array}$ \\
\hline 2.04 & 1.96 & 4.32 & 2.04 & 1.97 & 3.80 \\
\hline 3.24 & 3.68 & -11.82 & 3.24 & 3.70 & -12.43 \\
\hline 4.58 & - & - & 4.58 & 4.94 & -7.34 \\
\hline- & 11.76 & - & - & 12.00 & - \\
\hline
\end{tabular}


Table 4 Comparison between present-work results and previous-work results for three-quarter-filled tank

\begin{tabular}{|c|c|c|c|c|c|}
\hline $\begin{array}{l}\text { Present } \\
\text { method } \\
{[\mathrm{Hz}]}\end{array}$ & $\begin{array}{c}\text { Dupriez } \\
\text { (experimental) } \\
{[\mathrm{Hz}]}\end{array}$ & $\begin{array}{c}\begin{array}{c}\text { Relative } \\
\text { error }[\%]\end{array} \\
\frac{f_{p}-f_{p}}{f_{p}} \times 100\end{array}$ & $\begin{array}{l}\text { Present } \\
\text { method } \\
{[\mathrm{Hz}]}\end{array}$ & $\begin{array}{c}\text { Ohayon } \\
\text { (numerical) } \\
{[\mathrm{Hz}]}\end{array}$ & $\begin{array}{c}\text { Relative } \\
\text { error }[\%] \\
\frac{f_{p}-f_{0}}{f_{p}} \times 100\end{array}$ \\
\hline 2.24 & 2.22 & 0.94 & 2.24 & 2.16 & 3.55 \\
\hline 2.42 & - & - & 2.42 & 2.29 & 5.49 \\
\hline 3.63 & 3.90 & -6.87 & 3.63 & 4.00 & -9.24 \\
\hline 4.88 & 4.89 & -0.06 & 4.88 & 4.80 & 1.66 \\
\hline
\end{tabular}

\section{CONCLUSION}

Based on a standard general purpose finite element software, it was possible to evaluate the dynamic effect of the contained fluid on the modal characteristics of a free-free horizontal tank structure.

To resemble the influence of the fluid-structure interaction on the modal characteristics of the structure, a percentage of the fluid mass was added equally to the nodes of the wetted surface of the structure.

By the help of the available literature and the gained practice in manipulating such types of problems, a useful empirical equation was established. This equation enables to determine the mass equivalent to that of the fluid, to be added at the wetted nodes of the structure. The relative height of the fluid, defined as the ratio of fluid height to tank diameter is the independent variable of this equation. The analyses made by the present technique proved good agreement with the previous literature concerning both values and behavior.

\section{References:}

1. Zienkiewicz O.C. and Taylor L., "The Finite Element Method", McGraw Hill 1991

2. Zienkiewicz O.C. and Betess P., "Fluid-Structure Dynamic Interaction and Wave Forces. An Introduction to Numerical Treatment", International Journal for Numerical Methods in Engineering, 13, 1-16, 1978.

3. Hamdi M.A., Ousset Y. \& Verchery G., "A Displacement Method for the Analysis of Vibrations of Fluid-Structure Systems", Intemational Journal for Numerical Methods in Engineering, 13, 139-150, 1978.

4. Everstine G. C., "A symmetric Potential Formulation for Fluid-Structure InteractionLetter to the editor", Joumal of Sound and Vibration, Vol. 79(1), 157-160, 1981.

5. Wilson E. L. and Khalvat M., "Finite Element for the Dynamic Analysis of Fluid Solid Systems," International Journal for Numerical Methods in Engineering, Vol. 19, 1657 -
1668,1983

6. Chen H.C. and Taylor R. L.," Vibration Analysis of Fluid-Solid Systems Using a Finite Element Displacement Formulation", International Journal for Numerical Methods in
Engineering, Vol. 29, 683-698, 1990 
7. Zinkiewicz O.C., Kelly D.W. and Betess P., "The Coupling of the Finite Element Method and Boundary Solution Procedures", International Joumal for Numerical Methods in Engineering, 11, 355-375, 1977.

8. Beribia J., "Internal Fluid Problems", in Kardestuncer et al. (editor), "Finite Elernent Handbook, Part Three: FEM Applications, Chapter Five: Coupled Systerns ", McGraw-Hill Book Company, pp. 3.285-3.311, 1987.

9. Estroff O., "Coupling of BEM and FEM in the Time Domain: Some Remarks on its Applicability and Efficiency," Computers and Structures, VOL. 44, No.

10. Meirovitch L., "Computational Methods in Structural Dynamics, "Mechnics: Dynamical Systems, Sijhoff, Rockville, MD, 1980.

11. Giordano J.A. and Koopmann G.H., "State Space Boundary Element- Finite Element Coupling for Fluid-Structure Interaction Analysis", Journal of Acoustical Society of America, 98(1), 363-372, 1995

12. Mikami T. and Yoshimura J., "The Collocation Method for Analyzing Free Vibration of shells of Revolution with either Internal or external Fluids", Computers and Structures, Vol. 44(1/2), 343-351, 1992.

13. Lee L.T. and Lu J.C., "Free Vibration of Cylindrical Shells Filled with Liquid", Computers and Structures, 54(5), 997-1001, 1995.

14. Housner G. W., "Dynamic Behavior of Water Tanks," Bulletin of Seismological Society of America, Vol. (53), No. 2, pp. 381-387, 1963

15. El-Sherief F. S., Farghly S. H., Farghly M. H. and El-Mahdy T. H., "Analy:sis of Fluid Sloshing in Tanks for Vibration Control," Proc. of 1st ASAT Conf., MTC, Cairc, pp. 347-356, 1985

16. Qinque W. and Lidu H., "Eigen-Problem of Liquid-Container Coupling", Computers \&، Structures, Vol. 44, No. 1/2, pp.353-355, 1992

17. Ohayon R. and Valid R., "True Symmetric Variational Formulations for Fluich. structure Interaction in Bounded Domains - Finite Element Results", "Numerical Methods in Coupled Systems", Lewis R. W., Bettess P. , and Hinton E., JOHN WILEY \& SONS. , 1984.

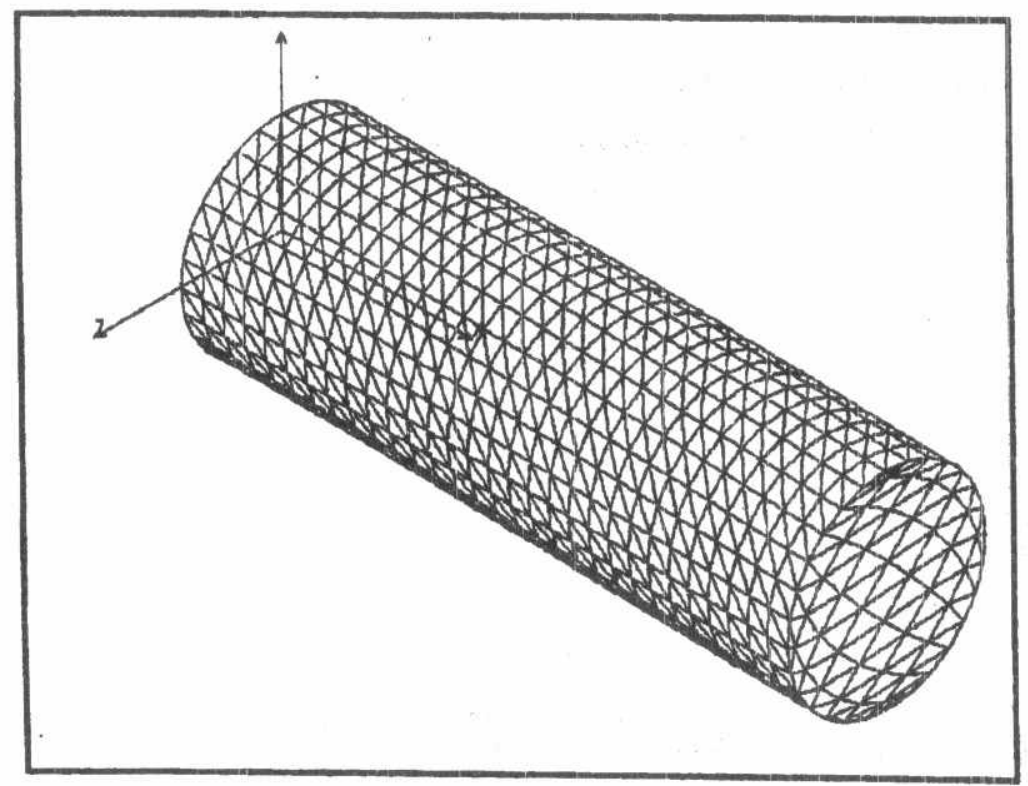




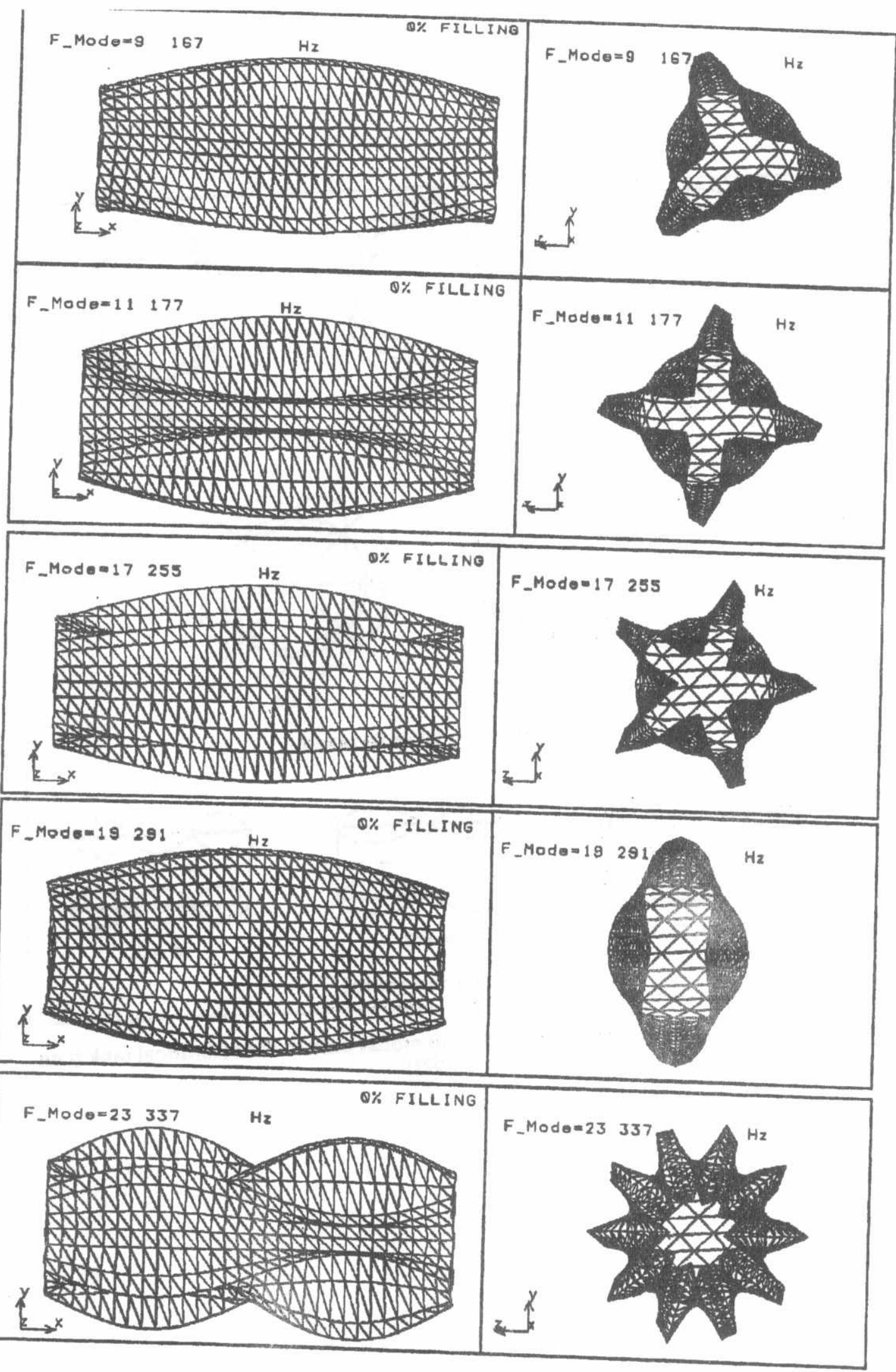

Fig.(2) First five mode shapes of the empty tank 


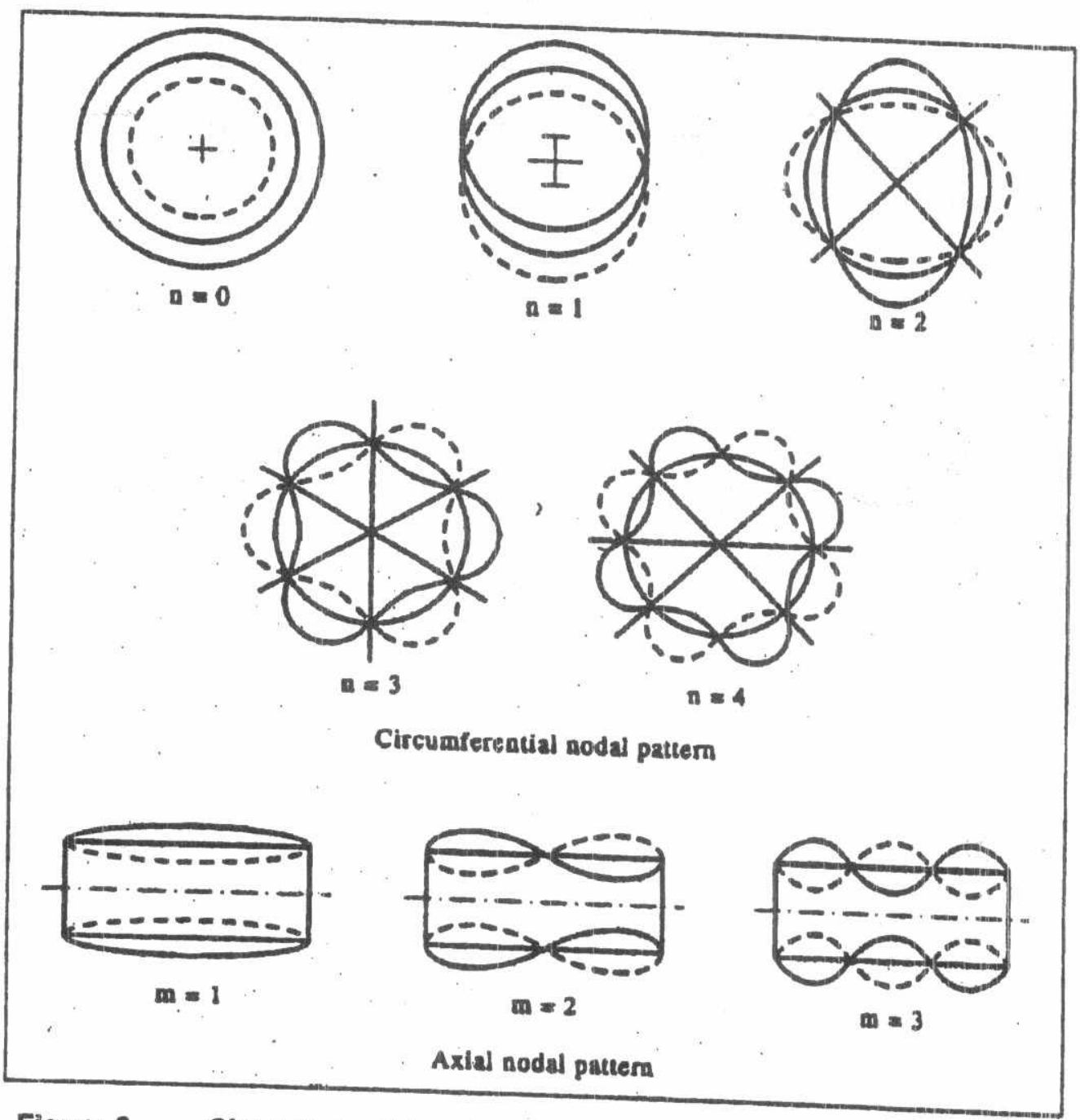

Figure 3

Circumferential and axial modal pattem for cylindrical tank (Leef
[27]) 


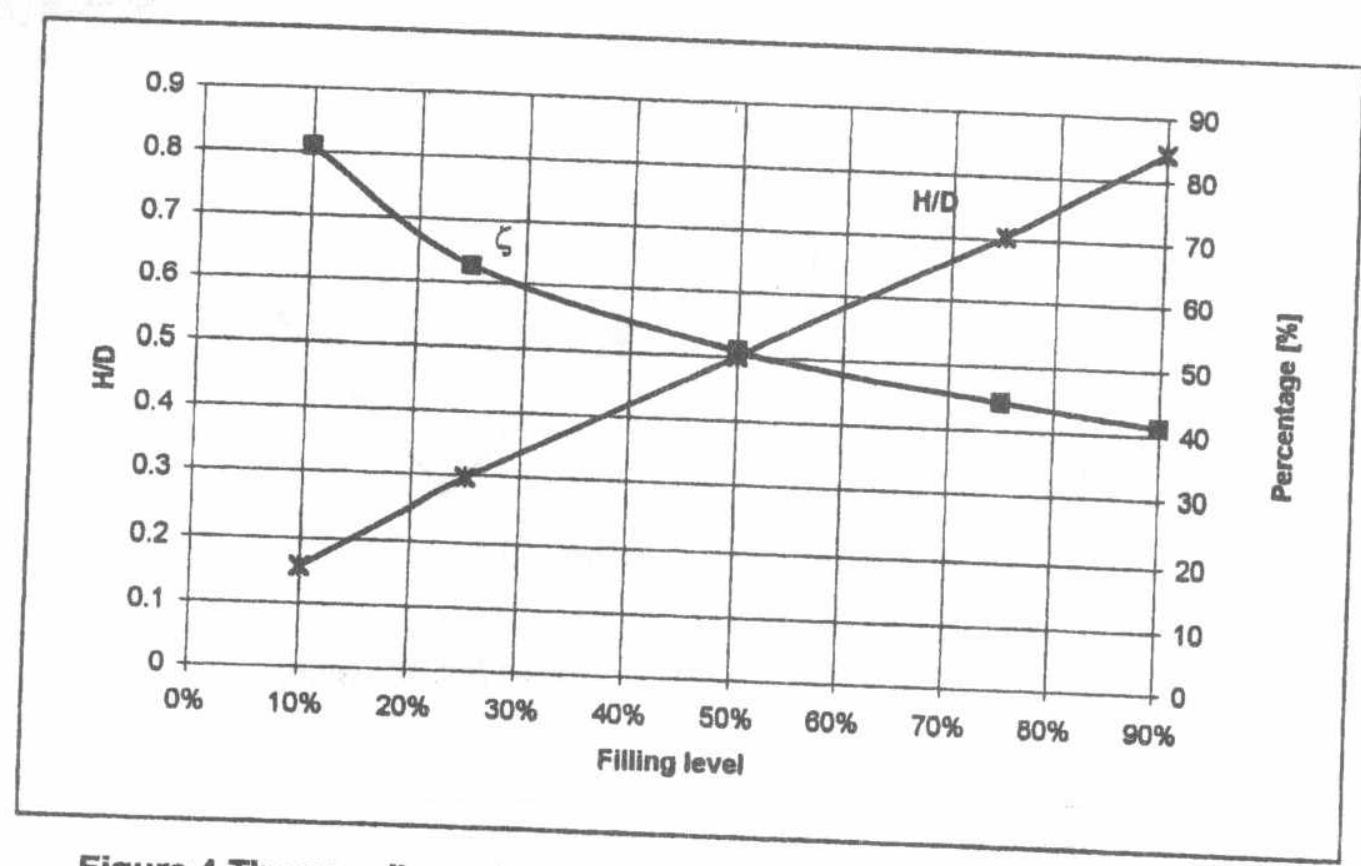
Figure 4 The non-dimensional height and the percentage function versus
filling level

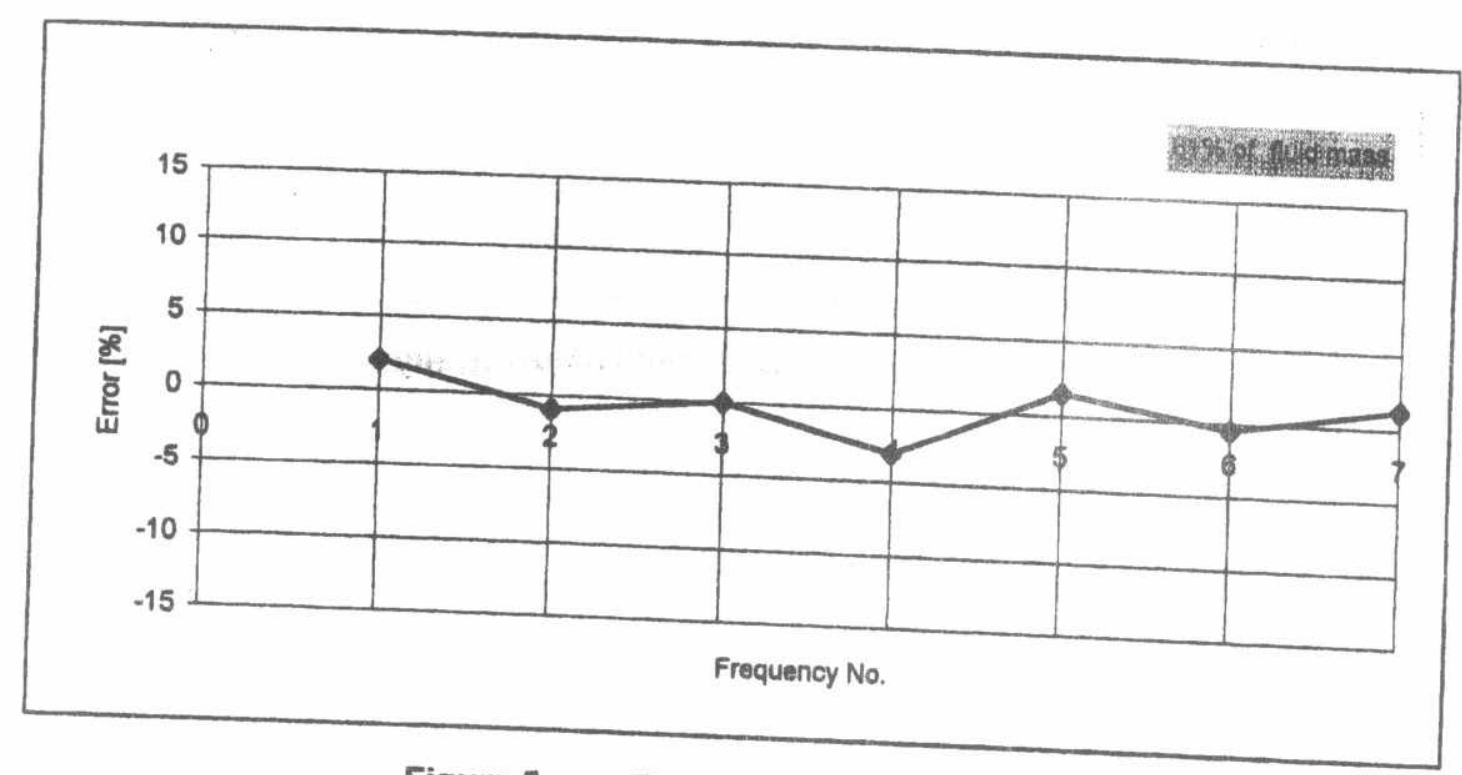

Figure 5 Error course for $10 \%$ filling 


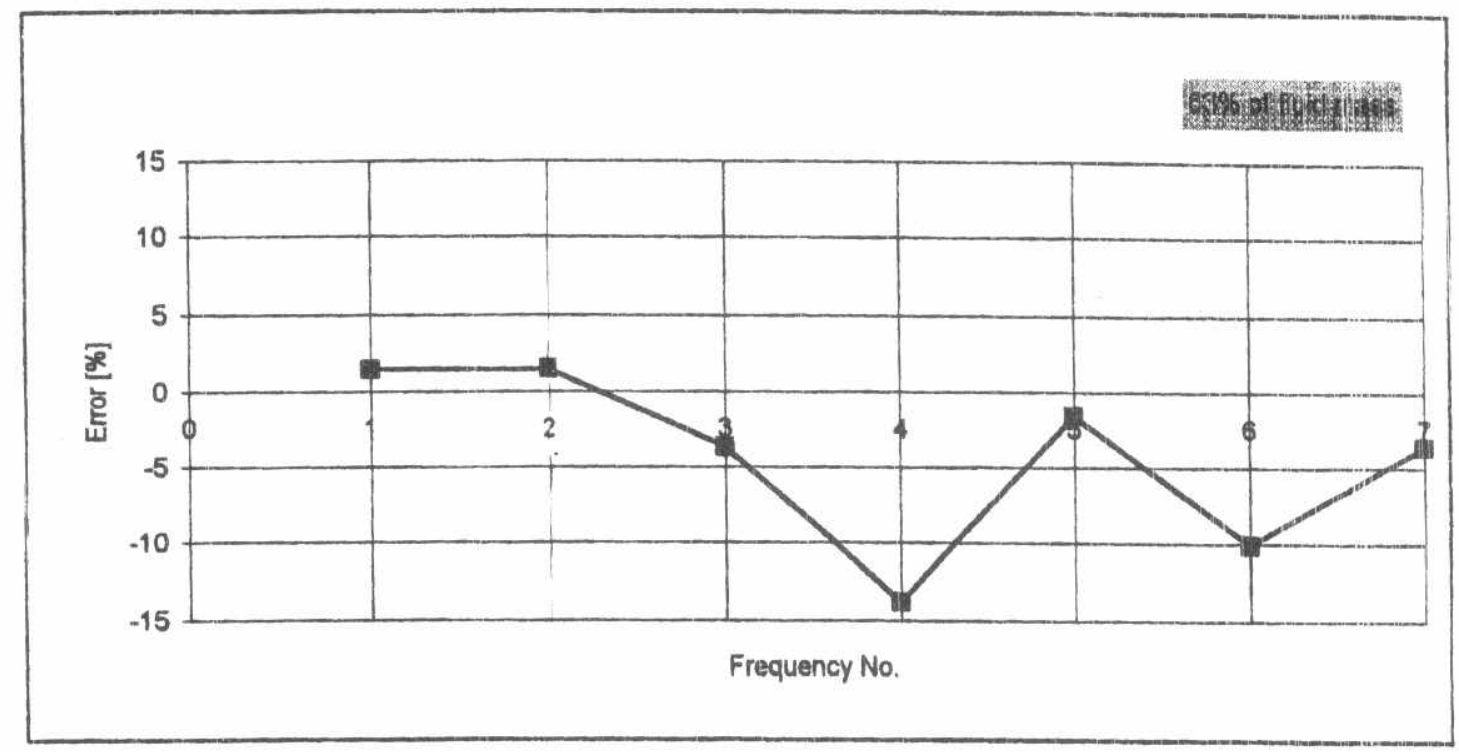

Figure 6 Error course for $25 \%$ filling

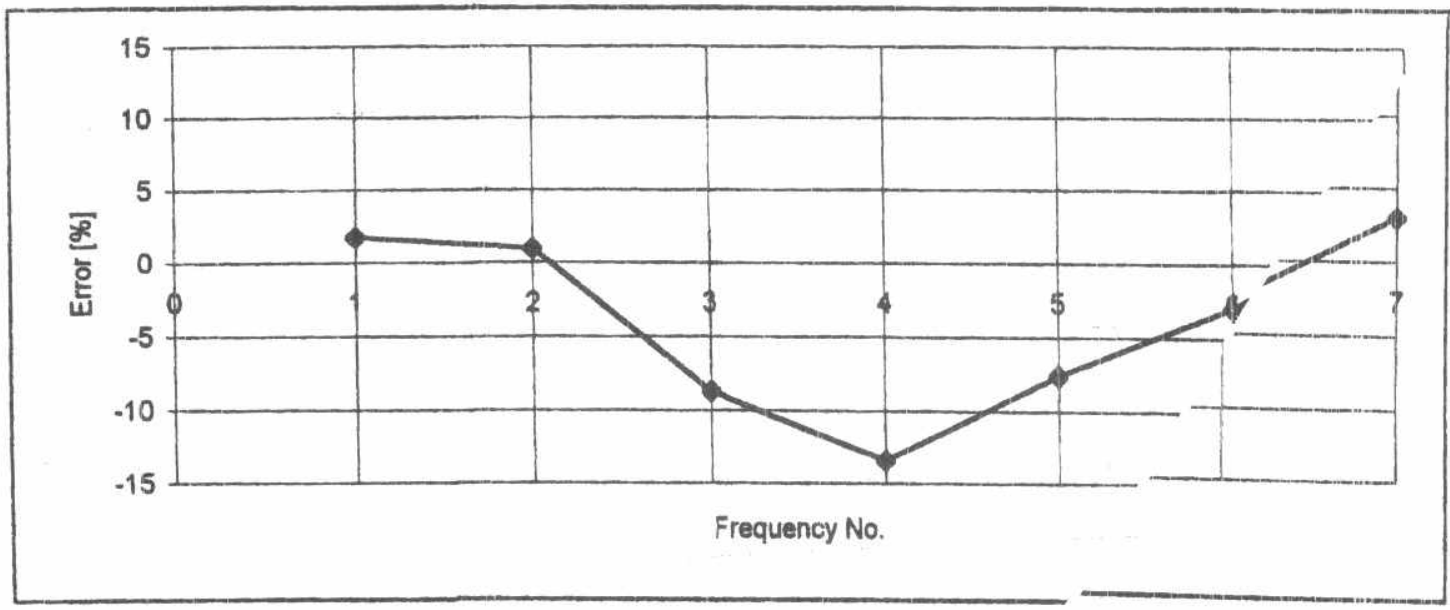

Figure 7 Error course for $\mathbf{5 0 \%}$ fillis 


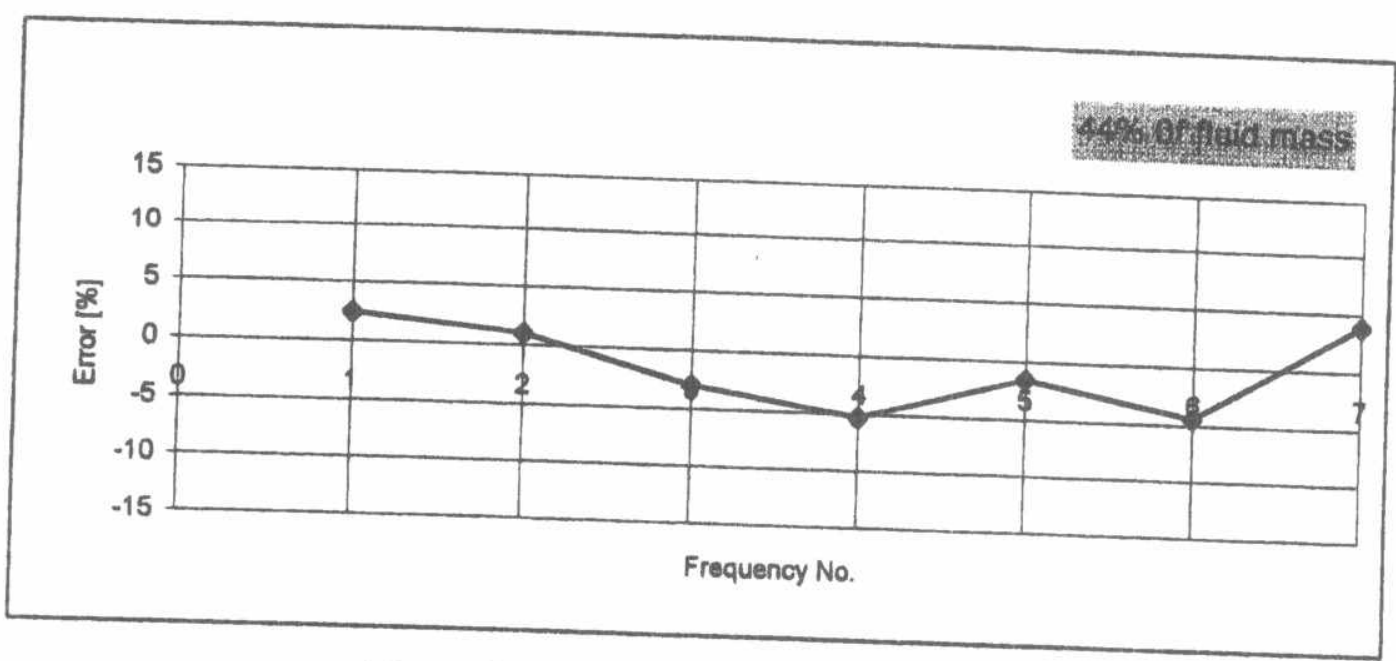

Figure 8 Error course for $75 \%$ filling

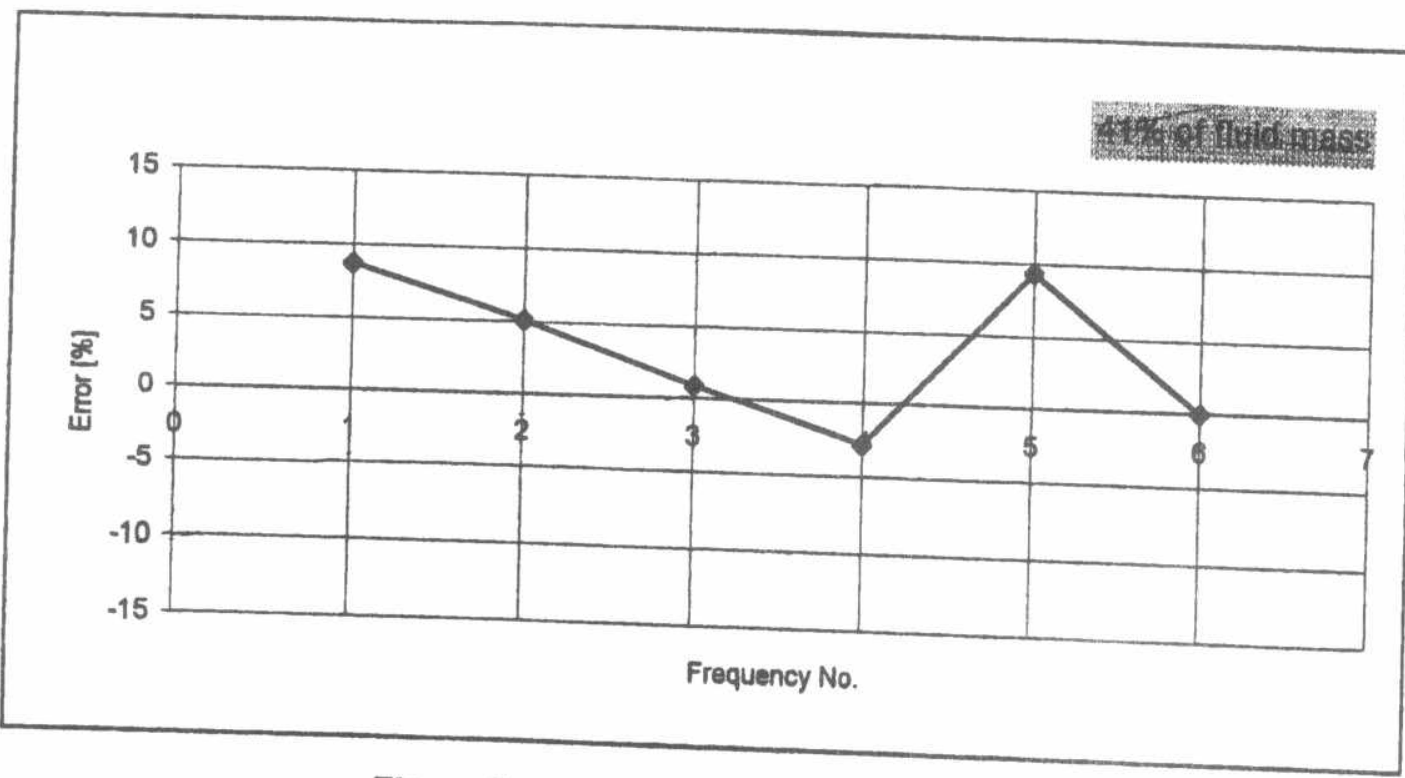

Figure 9 Error course for $90 \%$ filling 